\title{
Editorial
}

\section{Guests, ghosts and gofers}

\author{
Peter R. Mason \\ Biomedical Research \& Training Institute, P O Box CY1753 Causeway, Harare, Zimbabwe.
}

J Infect Developing Countries 2008; 2(2):78-80.

Received 06 February 2008 - Accepted 10 February 2008.

Copyright $@ 2008$ Mason. This is an open access article distributed under the Creative Commons Attribution License, which permits unrestricted use, distribution, and reproduction in any medium, provided the original work is properly cited.

Authorship of scientific articles is widely regarded as the one of the most objective of the criteria that can be used to determine academic achievement. As such, authorship is frequently used to assess the merit of academic promotion and subsequently of substantial social and financial benefit. In some cases the benefit may be direct (there are some institutions that give financial reward to authors from that institution) though usually the benefit is indirect in that authorship is an important factor in determining the outcome of grant applications. It is not surprising, therefore, that there is considerable pressure on individual scientists to ensure that their names are included on every possible paper, regardless of their actual contribution to the work that is being presented.

The opportunities for being included as an author are much greater now than in the past, with a growing number, size and diversity of collaborative projects leading to an ever increasing number of papers being published in an ever increasing number of journals [1]. Collaborative, multi-disciplinary studies have become the mainstay of high quality research in health, and perhaps the majority of publications in international journals from developing countries now stem from international collaborative research projects. One of the characteristics of scientific publication has been the rapid change from single-author papers to multi-author papers [2,3]. In his note on "the demise of the lone author", Matt Greene points out that while issues of Nature contain about as many articles now as they did in the 1950s, there are about four times as many authors [4]. These changes in authorship patterns can also be seen in publications from developing countries.
Editors of scientific journals have a responsibility to apply the principles of ethical authorship, ensuring that authorship is based on merit and not just on status [5]. In this context, scientific research literature depends to a great degree on trust [6] - the authors have to trust editors and reviewers to conduct an honest and unbiased assessment of the article and in return the editors have to trust that the data (including the author list) are presented honestly and completely. Authorship, however, still remains one of the most contentious issues in scientific publishing, and some of these issues have particular importance in the framework of international collaborative studies that are based in developing countries.

There are a number of different criteria that can be used to determine the merit of inclusion as an author. The most frequently cited are the guidelines of the International Committee of Medical Journal Editors (ICMJE), which have been updated in recent years [7]. The ICMJE suggest that "authorship credit should be based on 1) substantial contribution to conception and design, or acquisition of data, or analysis and interpretation of data; 2) drafting the article or revising it critically for important intellectual content; and 3) final approval of the version to be published." Furthermore, the authors must be able to take responsibility for the content of the article and be able to respond to critical appraisal. Some journals use these guidelines expressly, or in modified form, though for many journals the requirements for authorship are unclear, with less than $40 \%$ of journals reviewed in one study giving no guidance on authorship at all [8]. The criteria for authorship may also be unclear to researchers and their graduate students [9]. In such situations it 
may be difficult for the reader to know who really did the work that has been published, and thereby be able to determine whether the paper is credible.

There are three situations that editors come across frequently: "guest" authorship, "ghost" authorship and "gofer" authorship. Guest authors are those "important" persons who insist that their names appear on the papers of their juniors, even when they have made minimum contribution to the research. Ghost authors are those who make a significant contribution to the writing of a paper, but their names do not appear as an author on the publication. This is often a situation found in clinical trials sponsored by pharmaceutical companies. These companies may consider that inclusion of their own writer may diminish the credibility of the publication since there is an obvious conflict of interest. Ghost authorship may be very common - one recent study showed evidence of ghost authorship in $75 \%$ of 44 industry-initiated clinical trials [10]. A "gofer" is a name given to someone who is regarded as very junior and so is sent to "go for" something and bring it back to the more important members of a team. In research this often refers to juniors whose task is only to collect specimens or data, but who make no contribution to study design or data analysis or to the final manuscript.

In some cases it may be readily seen that a particular paper may not have applied the correct criteria. For example, it may be considered very unlikely that 12 authors would all have made a significant contribution to the writing of a case report-and it would be reasonable for an editor to suspect that some authors may have been included as "guest" authors. Similarly a complex study involving clinical, epidemiological, laboratory, sociological, and statistical expertise is unlikely to have been conducted by any less than four or five researchers. If only two authors are included on a paper from such a study, doubts may be raised whether this was in fact correct or whether some "ghost" authors had been removed. Finally consider a paper that describes the use of complex technology to characterize an organism from a developing country-and only one of the 12 authors is from that country. It is highly probable that this person is a "gofer" author whose role was to collect specimens and arrange shipment overseas to a laboratory in the developed world, but who played no part in the other more intellectual parts of the study. According to ICJME criteria, this is not sufficient to justify authorship.

According to the ICJME, activities that do not merit authorship include "acquisition of funding, collection of data or specimens, and general supervision of research groups" [7]. Many instances of authorship from the developing world may not be compatible with these criteria. The JIDC has an additional responsibility-that of encouraging and supporting the full participation of researchers in developing countries in the dissemination of research findings. The question is whether this editorial responsibility supersedes the responsibilities arising from international guidelines on publication ethics. There may be many situations where an international collaborative study arises from a design that was prepared in a developed country, and where the analysis and writing are also largely if not completely under the control of the developed country researchers. The role of the developing country researchers is then mainly a technical role-that of specimen and data collection-rather than an intellectual role. According to ICMJE criteria, and most other guidelines, inclusion of the developing country researchers as authors goes against publication ethics and including them as gofer authors may be described as "scientific paternalism". But others may argue that not including at least one of the developing country researchers may be construed as "scientific imperialism"-using the resources of the developing country for the benefit only of the developed country, and there is a sense that this is morally unacceptable. Clearly these are difficult issues that need careful consideration and comment from the scientific community. The views of researchers, particularly researchers living or working in developing countries, would be most welcome.

The position of JIDC is that as an international journal that aspires to improve capacity for scientific writing by researchers from developing countries, there is no merit in scientific paternalism or in encouraging "gofer" or "guest" authorship. If the goal is improving capacity, then a requisite of achieving capacity building is to ensure that scientists from developing countries have an equal standing in the scientific community as scientists from resource rich nations.. Therefore, while JIDC welcomes submissions from those in developing countries, the international requirements of authors 
must be respected. The JIDC will continue to adhere to those international criteria in the editorial and peer review processes, including the ethics that apply to authorship. In conformity with other international journals, and with the recommendations of ICJME, the JIDC will now also require brief statements of the role of each author in the research being described. These statements will be included in the article so that readers themselves can decide the credibility of the article. The JIDC encourages international researchers to ensure that colleagues in developing countries are actively involved in research design, analysis, and writing so that the capacity for conducting independent research can grow and so that developing country scientists can take an active role in the international scientific community.

\section{References}

1. Katsouyanni K. (2008) Collaborative research: accomplishments and potential. Environmental Health $7: 1$.

2. Regaldo A. (1995) Multiauthor papers on the rise. Science 268:25.

3. Shaba S. (2007) Multiauthorship trends in prestigious journals from 1950 to 2005. Saudi Medical Journal 28:927-32.

4. Greene M. (2007) The demise of the lone author. Nature 450:1165.

5. Bury B. (2007) Authorship: must be earned, not assumed. Clinical Radiology 62:917-18.

6. Graf C, Wager E, Bowman A, Flack S, Scott-Licher D, Robinson A. (2007) Best Practice guidelines on publication ethics: a publisher's perspective. International Journal of Clinical Practice 61(Suppl 152):1-26.

7. International Committee of Medical Journal Editors. Uniform requirements for manuscripts submitted to biomedical journals: writing and editing for biomedical publication. Available at www.icmje.org Updated October 2007.

8. Wager E. (2007) Do medical journals provide clear and consistent guidelines on authorship? Medscape General Medicine 9.

9. Hren D, Sambunjak D, Ivanis A, Marusic M, Marusic A. (2007) Perceptions of authorship criteria: effects of student instruction and scientific experience. Journal of Medical Ethics 33:428-32.

10. Gotzsche PC et al. (2007) Ghost authorship in industryinitiated randomized trials. PLoS Medicine 4 (1).
Corresponding Author: Peter R. Mason, Biomedical Research \& Training Institute, P O Box CY1753 Causeway, Harare, Zimbabwe. E-mail: pmason@zol.co.zw

Conflict of interest: No conflict of interest is declared. 